\title{
Behaviour of radioactive iodide and bromide ions from aqueous solution on ion exchange resins Amberlite IRA-400
}

\author{
Pravin Singare $^{1^{*}}$, Ram Lokhande ${ }^{2}$ \\ ${ }^{1}$ Department of Chemistry, Bhavans College, Mumbai, India \\ ${ }^{2}$ Department of Chemistry, University of Mumbai, Mumbai, India
}

Received 15 June 2009; revised 2 July 2009; accepted 5 July 2009.

\begin{abstract}
The ion exchange resin Amberlite IRA-400 in iodide and bromide form where equilibrated separately with the respective labeled iodide and bromide ion solution of different concentrations varying from $0.005 \mathrm{M}$ to $0.100 \mathrm{M}$ in the temperature range of $32.0^{\circ} \mathrm{C}$ to $48.0^{\circ} \mathrm{C}$. The distribution coefficient $K_{d}$ values calculated for iodide and bromide ion exchange increases with rise in ionic concentration of the external solution, however with rise in temperature the $K_{d}$ values calculated where found to decrease. Also the $K_{d}$ values calculated where higher for iodide exchange than bromide exchange. Among the different alternative techniques available for obtaining the $K_{d}$ values, the radioactive tracer technique used in the present experimental work offers high detection sensitivity. It is expected that the distribution coefficient data obtained from such experimental work will significant in environmental impact assessment on the disposal of radioactive waste.
\end{abstract}

Keywords: Ion Exchange Resin; Amberlite IRA-400; Distribution Coefficient; Temperature Effect; Concentration Effect; ${ }^{131} \mathrm{I} ;{ }^{82} \mathrm{Br}$; Radioactive Tracer Isotope

\section{INTRODUCTION}

There are number of liquid processes and waste streams at nuclear power plants, fuel reprocessing plants and nuclear research centers that require treatment for removal of radioactive contaminants. One of the most common treatment methods for such aqueous streams is the use of ion exchange, which is a well developed technique that has been employed for many years in nuclear industries $[1,2]$. The ion exchange process is very effec- tive at transferring the radioactive content of a large volume of liquid into a small volume of solid. Efforts to develop new ion exchangers for specific applications are continuing. In spite of their advanced stage of development, various aspects of ion exchange technologies have been continuously studied to improve the efficiency and economy of their application in radioactive waste management. The selection of an appropriate ion exchange material for the liquid radioactive waste treatment is possible on the basis of information provided by the manufacturer. However since the selection of the appropriate ion exchange material depends on the needs of the system, it is expected that the data obtained from the actual experimental trials will prove to be more helpful. Generally the selected ion exchange materials must be compatible with the chemical nature of the radioactive liquid waste such type and concentration of ionic species present as well as the operating parameters notably temperature. Also while designing an ion exchange processing system it is desirable to have an adequate knowledge of the distribution coefficient values of the ion exchange resin towards different ions present in radioactive liquid waste. These distribution coefficients are very important parameter for environmental impact assessment on the disposal of radioactive waste arising from research institutes [3].

Although there are different alternative methods available to know the distribution coefficient values, but radioactive isotopic technique is expected to be the most appropriate method as it offer several advantages such as high detection sensitivity, capability of in-situ detection, and physico-chemical compatibility with the material under study [4-8]. Attempts where made by the previous researchers to study the concentration and temperature effect on cation exchange systems for computing the distribution coefficient values [9-15]. However very little work was done to study the distribution coefficient values in anion exchange systems [16]. Therefore, in the present investigation, attempts where made to study the effect of external ionic concentration and temperature on 
distribution coefficient, for which radioactive tracer technique was used.

\section{EXPERIMENTAL}

Ion exchange resin Amberlite IRA-400 (by Rohm and Haas Company, USA), was a strongly basic anion exchange resin in chloride form. The resins where converted in iodide and bromide form by eluting with $10 \%$ $\mathrm{KI}$ and $\mathrm{KBr}$ solution in a conditioning column. The $1.000 \mathrm{~g}(\boldsymbol{m})$ of conditioned resins in iodide and bromide form was equilibrated separately with labeled $250 \mathrm{~mL}(\boldsymbol{V})$ of $0.005 \mathrm{M}$ iodide and bromide ion solution respectively under continuous and uniform mechanical stirring. The solution was uniformly stirred using the mechanical stirrer for $3 \mathrm{~h}$ at a constant temperature of $32.0{ }^{0} \mathrm{C}$ so as to attain equilibrium.

The ion exchange reaction taking place can be represented as follows:

$$
\begin{gathered}
\mathrm{R}-\mathrm{I}^{+\mathrm{I}^{*-}}{ }_{\text {(aq.) }} \rightleftharpoons \mathrm{R}-\mathrm{I}^{*}+\mathrm{I}^{-} \text {(aq.) } \\
\mathrm{R}-\mathrm{Br}+\mathrm{Br}^{*^{-}} \text {(aq.) } \rightleftharpoons \mathrm{R}-\mathrm{Br}^{*}+\mathrm{Br}^{-} \text {(aq.) }
\end{gathered}
$$

where $\mathrm{I}^{*^{-}}$(aq.) and $\mathrm{Br}^{*^{-}}$(aq.) represent aqueous solution of iodide and bromide labeled with radioactive isotope ${ }^{131} \mathrm{I}$ and ${ }^{82} \mathrm{Br}$ respectively.

The initial activity $\left(\boldsymbol{A}_{\boldsymbol{i}}\right)$ and final activity $\left(\boldsymbol{A}_{\boldsymbol{f}}\right)$ in counts per minutes (c.p.m.) of the labeled solutions was measured on $\gamma$-ray spectrometer having $\mathrm{Na}$ (I) $\mathrm{Tl}$ scintillation detector. From the knowledge of $\boldsymbol{A}_{\boldsymbol{i}}$ and $\boldsymbol{A}_{\boldsymbol{f}}$, the $\boldsymbol{K}_{\boldsymbol{d}}$ value was calculated by the equation

$$
\boldsymbol{K}_{\boldsymbol{d}}=\left[\left(\mathrm{A}_{\mathrm{i}}-\mathrm{A}_{\mathrm{f}}\right) / \mathrm{A}_{\mathrm{f}}\right] \times \mathrm{V} / \mathrm{m}
$$

The experimental sets where repeated in the same manner by increasing the ionic concentrations up to $0.100 \mathrm{M}$ and the temperature varying up to $48.0^{\circ} \mathrm{C}$. The $\boldsymbol{K}_{\boldsymbol{d}}$ values for different sets where calculated by Eq.3.

The ${ }^{82} \mathrm{Br}$ isotope used was an aqueous solution of ammonium bromide in dilute ammonium hydroxide having activity $5 \mathrm{mCi}, \gamma$ - energy $0.55 \mathrm{MeV}$, and $\mathrm{t}_{1 / 2} 36 \mathrm{~h}$. The ${ }^{131} \mathrm{I}$ isotope used was an aqueous solution of sodium iodide in dilute sodium sulfite, having activity $5 \mathrm{mCi}, \gamma$ energy $0.36 \mathrm{MeV}$, and $\mathrm{t}_{1 / 2} 8.04 \mathrm{~d}[17]$.

\section{RESULTS AND DISCUSSIONS}

In the present research work the ion exchange resin in iodide and bromide form where equilibrated for $3 \mathrm{~h}$ with labeled iodide and bromide ion solution respectively of known initial activity. From the results of previous work [4-8,18-24]; it was observed that this time duration was sufficient to attain equilibrium. Due to ion isotopic exchange reactions taking place the activity of the solution decreases with time. The decrease in activity of the solu

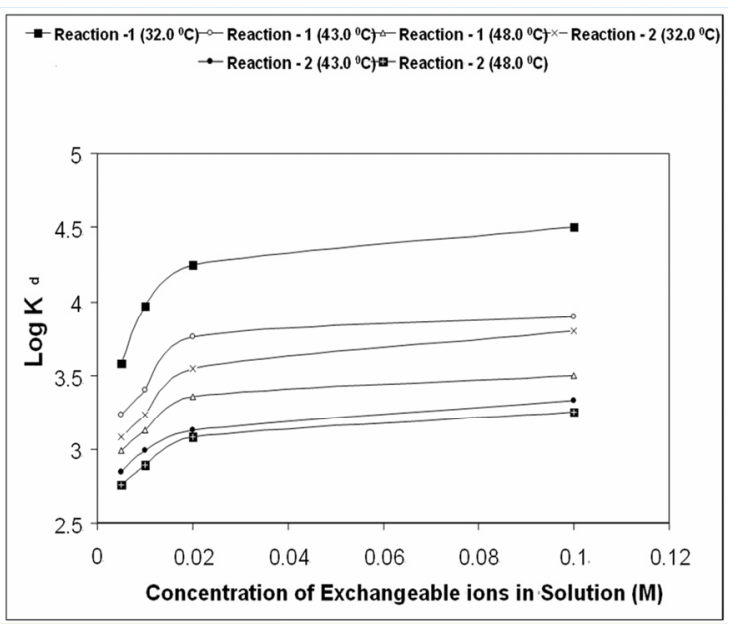

Figure 1. Variation of distribution coefficient with ionic concentration and temperature.

Table 1. Effect of ionic concentration on distribution coefficients. Temperature $=32.0{ }^{\circ} \mathrm{C}$, amount of resin $=1.000 \mathrm{~g}$, volume of solution $=250 \mathrm{~mL}$.

\begin{tabular}{ccc}
\hline \multirow{2}{*}{$\begin{array}{c}\text { Concentration } \\
(\mathrm{M})\end{array}$} & \multicolumn{2}{c}{ Log Kd } \\
\cline { 2 - 3 } & Iodide ions & Bromide ions \\
\hline 0.005 & 3.58 & 3.08 \\
0.010 & 3.97 & 3.23 \\
0.020 & 4.25 & 3.55 \\
0.100 & 4.50 & 3.80 \\
\hline
\end{tabular}

Table 2. Effect of temperature on distribution coefficients Concentration of labeled ionic solution $=0.005 \mathrm{M}$, amount of resin $=1.000 \mathrm{~g}$, volume of solution $=250 \mathrm{~mL}$.

\begin{tabular}{ccc}
\hline \multirow{2}{*}{${ }^{\text {Temperature }} \mathrm{C}$} & \multicolumn{2}{c}{ Log Kd } \\
\cline { 2 - 3 } & Iodide ions & Bromide ions \\
\hline 32.0 & 3.58 & 3.08 \\
43.0 & 3.23 & 2.85 \\
48.0 & 2.99 & 2.76 \\
\hline
\end{tabular}

tion was measured after $3 \mathrm{~h}$ which represent the final activity exchanged on the resin. From the knowledge of initial and final activity, the $\boldsymbol{K}_{\boldsymbol{d}}$ values where calculated by Eq.3 to study the effect of temperature and concentration. Heumann et al. [16] in the study of chloride distribution coefficient on strongly basic anion-exchange resin observed that the selectivity coefficient between halide ions increases at higher electrolyte concentrations. Adachi et al. [9] observed that the swelling pressure of 
the resin decreased at higher solute concentrations resulting in larger distribution coefficient values. The temperature dependence of the distribution coefficient on cation exchange resin was studied by Shuji et al. [11], they observed that the distribution coefficients increased with decreasing temperature. The present experimental results also indicates that the distribution coefficient $\boldsymbol{K}_{\boldsymbol{d}}$ values calculated for iodide and bromide ions increases with increase in ionic concentration of the external solution (Table 1), however with rise in temperature the $\boldsymbol{K}_{\boldsymbol{d}}$ values calculated where found to decrease (Table 2). Also the $\boldsymbol{K}_{\boldsymbol{d}}$ values calculated where higher for iodide ions as compared to that for bromide ions (Tables $\mathbf{1}$ and 2). The variation of $\boldsymbol{K}_{\boldsymbol{d}}$ values for iodide and bromide ions with temperature and concentration of external ionic solution is graphically represented in Figure 1.

\section{CONCLUSIONS}

In heavy metal removal processes the rate of removal is considered to be important factor from the practical aspect of reactor design and process optimization [25]. Earlier research was performed demonstrating the feasibility of using the bioresin in a continuous system for decontaminating pool water of ${ }^{60} \mathrm{Co}$ [26]. It is important here to note that in all the above decontamination processes, distribution coefficient $\boldsymbol{K}_{\boldsymbol{d}}$ values plays a very prominent role in deciding about proper selection of resins. The work carried out in the present experiment is a demonstration showing application of radioactive active tracer technique to study the parameters affecting the distribution coefficient. The same technique can be extended further to study the $\boldsymbol{K}_{\boldsymbol{d}}$ values of different ion exchange resins for various ions in liquid radioactive waste. The data base so obtained on $\boldsymbol{K}_{\boldsymbol{d}}$ value will serve as a very important parameter for environmental impact assessment on the disposal of radioactive waste [3].

\section{REFERENCES}

[1] (1967) International atomic energy agency, operation and control of ion exchange processes for treatment of radioactive wastes. Technical Reports Series, 78, IAEA, Vienna.

[2] (1984) International atomic energy agency, treatment of low- and intermediate-level liquid radioactive wastes. Technical Reports Series, 236, IAEA, Vienna.

[3] T. Shin'ichi and A. Masayoshi, (2001) Development of database on the distribution coefficient. Preparation of Database, Nippon Genshiryoku Kenkyujo JAERI, Data, Code, 102(2).

[4] R. S. Lokhande, P. U. Singare, and A. B. Patil, (2007) Application of radioactive tracer technique on industrial grade ion exchange resins Indion-830 (Type-1) and Indion-N-IP (Type-2). Radiochim. Acta, 95(1), 111-114.
[5] R. S. Lokhande, P. U. Singare, and A. R. Kolte, (2007) Study on kinetics and mechanism of ion-isotopic exchange reaction using strongly basic anion exchange resins Duolite A-101 D and Duolite A-102 D. Radiochim. Acta, 95(10), 595-600.

[6] R. S. Lokhande, P. U. Singare, and P. Karthikeyan, (2007) The kinetics and mechanism of bromide ion isotope exchange reaction in strongly basic anion-exchange resin Duolite A-162 determined by the radioactive tracer technique. Russ. J. Phys. Chem., A, 81(11), 1768-1773.

[7] P. U. Singare, R. S. Lokhande, and A. B. Patil, (2008) Application of radioactive tracer technique for characterization of some strongly basic anion exchange resins, Radiochim. Acta, 96(2), 99-104.

[8] R. S. Lokhande, P. U. Singare, and T. S. Prabhavalkar, (2008) The application of the radioactive tracer technique to study the kinetics of bromide isotope exchange reaction with the participation of strongly basic anion exchange resin Indion FF-IP. Russ. J. Phys. Chem., A, 82(9), 1589-1595.

[9] S. Adachi, T. Mizuno, and R. Matsuno, (1995) Concentration dependence of the distribution coefficient of maltooligosaccharides on a cation-exchange resin. J. Chromatography A, 708(2), 177-183.

[10] S. Adachi, T. Watanabe, and M. Kohashi (1989) Role of swelling pressure on the distribution coefficient of maltooligosaccharide in a cation-exchange resin, Agricultural and Biological Chemistry, 53(12), 3203-3208.

[11] A. Shuji, M. Takcshi, and M. Ryuichi, (1996) Temperature dependence of the distribution coefficient of maltooligosaccharides on cation-exchange resin in $\mathrm{na}^{+}$form. Bioscience, Biotechnology, and Biochemistry, 60(2), 338-340.

[12] S. Adachi and R. Matsuno, (1999) Apparent distribution coefficients of glucose and fructose to cation-exchange resins in some ionic forms. J Appl Glycosci, 46(1), 9-14.

[13] T. N. Van Der Walt and P. P. Coetzee, (1996) Distribution coefficients and ion exchange behaviour of some elements with Purolite S-950 in hydrochloric acid. Anal Bioanal Chem., 356(7), 420-424.

[14] F. W. E. Strelow, (1986) The influence of resin loading on cation exchange distribution coefficients of some elements in hydrochloric acid. Solvent Extraction and Ion Exchange, 4(6), 1193-1208.

[15] P. R. Sangurdekar, J. S. Melo, and S. F. D. Souza, (2005) Proceedings of Nuclear and Radiochemistry Symposium, Amritsar, India, 361.

[16] K. G. Heumann and K. Baier, (1982) Chloride distribution coefficient on strongly basic anion-exchange resin Dependence on co-ion in alkali fluoride solutions. Chromatographia, 15(11), 701-703.

[17] D. D. Sood, A. V. R. Reddy, S. R. K. Iyer, S. Gangadharan, and G. Singh, (1998) Proceedings of international conference on applications of radioisotopes and radiation in industrial development. Ed. Mumbai, India, 47.

[18] R. S. Lokhande, P. U. Singare, and M. H. Dole (2006) Comparative study on bromide and iodide ion-isotopic exchange reactions using strongly basic anion exchange resin Duolite A-113. J. Nuclear and Radiochemical Sciences, 7(2), 29-32.

[19] R. S. Lokhande, P. U. Singare, and M. H. Dole, (2007) Application of radiotracer technique to study the ion iso- 
tope exchange reactions using a strongly basic anionexchange resin Duolite A-113. Radiochemistry, 49(5), 519-522.

[20] R. S. Lokhande and P. U. Singare, (2007) Comparative study on ion-isotopic exchange reaction kinetics by application of tracer technique, Radiochim. Acta, 95(3), 173-176.

[21] R. S. Lokhande and P. U. Singare, (2008) Comparative study on iodide and bromide ion-isotopic exchange reactions by application of radioactive tracer technique. J. Porous Mater, 15(3), 253-258.

[22] R. S. Lokhande, P. U. Singare, and V. V. Patil, (2008) Application of radioactive tracer technique to study the kinetics and mechanism of reversible ion-isotopic exchange reaction using strongly basic anion exchange resin Indion-850. Radiochemistry, 50(6), 638-641.
[23] R. S. Lokhande, P. U. Singare, and S. A. Parab, (2008) Application of radioactive tracer technique to study the kinetics of iodide ion- isotopic exchange reaction using strongly basic anion exchange resin Duolite A-116. Radiochemistry, 50(6), 642-644.

[24] R. S. Lokhande, P. U. Singare, and S. R. D. Tiwari, (2008) Study of bromide ion-isotopic exchange reaction kinetics using a weakly basic macro porous resin Indion-860. Radiochemistry, 50(6), 633-637.

[25] J. H. Suh and D. S. Kim, (2000) Comparison of different sorbents (inorganic and biological) for the removal of $\mathrm{Pb}^{2+}$ from aqueous solutions. J. Chem. Technol. Biotechnol., 75(4), 279-284.

[26] P. R. Sangurdekar, J. S. Melo, S. F. D. Souza, and D. P. Pimputkar, (2003) Proceedings of Nuclear and Radiochemistry Symposium, BARC, Mumbai, India, 545. 